Biochimica et Biophysica Acta

Elsevier Publishing Company, Amsterdam - Printed in The Netherlands

BBA 35825

\title{
RELATIONSHIP BETWEEN THE CONFORMATION OF BOVINE SERUM ALBUMIN AND ITS DIGESTION BY PEPSIN
}

\author{
W. G. M. BRAAM, B. J. M. HARMSEN AND G. A. J. VAN OS \\ Department of Biophysical Chemistry, University of Nijmegen, Nijmegen (The Netherlands)
}

(Received October 3oth, 1970)

\section{SUMMARY}

I. The digestion of bovine serum albumin by pepsin in the $\mathrm{pH}$ region of the Normal-Fast transition was studied by means of electrophoresis on polyacrylamide gels. The results suggest a close relationship between the conformation of the albumin molecule and its digestion by pepsin.

2. At $\mathrm{pH}$ values just above 3.6 ten well-defined fragments were found. These features might support a model of albumin in which there are only a few, possibly three sites, available for hydrolysis by pepsin.

3. At $\mathrm{pH}$ values below 3.6 the more complex electrophoretic patterns suggest the existence of more sites, probably as a consequence of unfolding of the albumin molecule.

\section{INTRODUCTION}

The behaviour of albumin at low $\mathrm{pH}$ has been the subject of many investigations $^{1-6}$. A model which accounts for nearly all conformational transitions observed around $\mathrm{pH}_{4}$ has been proposed by Foster ${ }^{7}$. This model is an extension of the model of HARRINGTON et al. ${ }^{3}$ which was designed to account for the Normal-Fast transition, i.e. the transition from the normal electrophoretic mobility to a faster one upon lowering the $\mathrm{pH}$. In this model it is suggested that the molecule consists of four compact units linked by short randomly coiled polypeptide chains. Optical rotatory ${ }^{6}$ and viscosity ${ }^{2}$ data reveal that three stages can be distinguished in the behaviour of albumin at low $\mathrm{pH}$. In the $\mathrm{pH}$ range 4.5 to 3.9 at least two cooperative steps are observed $^{5}$. Between $\mathrm{pH} 3.9$ and 3.6 a plateau, i.e. very little change in various physical parameters, is found. Below $\mathrm{pH} 3.6$ a further change in optical rotation and viscosity appeared to occur ${ }^{1,2,5,6}$. According to the model proposed by FosTER ${ }^{7}$ these ubservations can be interpreted as an increase of the distance between the units from $\mathrm{pH} 4.5$ to 3.9 , a more or less stable situation between $\mathrm{pH} 3.9$ and 3.6 and a partial unfolding of the units below pH 3.6. WEBER AND YounG ${ }^{8}$ pointed out that at a $\mathrm{pH}$ where there is some distance between the units, a protease should preferentially act 
on the linking polypeptide chains, thus liberating a small number of fragments. They digested albumin with pepsin at $\mathrm{pH} 3.0$ and isolated two larger fragments. Later the isolation of several fragments obtained after short peptic digestion at $\mathrm{pH} 2.45$ (see ref. 9) and $\mathrm{pH} 3.0$ (see refs. IO, II), was reported. The amino acid sequence of an amino terminal peptide fragment has recently been determined ${ }^{\mathbf{1 0}, \mathbf{1 2}}$. It is, however, clear that upon lowering the $\mathrm{pH}$ an increasing number of sites becomes available for hydrolysis by a protease and therefore more fragments can be expected since a partial unfolding of the compact units occurs below $\mathrm{pH}$ 3.6. For this reason the influence of the $\mathrm{pH}$ on the proteoiytic hydrolysis of albumin should be carefully considered. We have therefore made a detailed study of the digestion of albumin by pepsin between $\mathrm{pH} 2.5$ and 4.5 .

\section{MATERIALS AND METHODS}

\section{Bovine serum albumin}

Bovine serum albumin (Nutritional Biochemicals Corp., $4 \times$ crystallised, lot No. 47I0) was deionized over a mixed bed ion exchange column (Amberlite IRA 400 and IR I20) giving an isoionic solution with a pH of about 5.2.

The SH group, present in about $60 \%$ of the bovine serum albumin molecules was blocked with iodoacetamide $(6 \mathrm{moles} / \mathrm{mole}$ bovine serum albumin) at $\mathrm{pH} 7.4$. After standing for one hour at room temperature the excess of reagent was removed by dialysis at $5^{\circ}$. Titration with $p$-chloromercuribenzoate at $\mathrm{pH} 4.6$ revealed that no reactive SH groups were present after this treatment.

Dimer-free albumin was obtained by gel filtration on Sephadex G-I50 in 0.I M $\mathrm{NaCl}$ at $5^{\circ}$. After dialysis the dimer-free albumin was concentrated by ultra filtration in a Diaflo Model 50 using a UM ro filter.

The protein concentration was determined spectrofotometrically, using $E_{\mathrm{r} \mathrm{cm}}^{\mathrm{x} \%}=6.67$ at $279 \mathrm{~nm}$.

\section{Peptic digestion}

Pepsin (porcine stomach mucosa, $3 \times$ crystallised, lot No. 800537 ) was obtained from Calbiochem (Switzerland). Only freshly prepared pepsin solutions were used. They were diluted to an absorbance of 0.5 at $279 \mathrm{~nm}$ in a I-cm cuvette and stored (for a short time) at $5^{\circ}$.

The digestion was carried out at $25^{\circ} \pm 0 . \mathrm{I}^{\circ}$ using Io $\mathrm{ml}$ of a $5 \%$ solution of albumin and $0.5 \mathrm{ml}$ of the pepsin solution (pepsin/albumin $=\mathrm{I}: 3000, \mathrm{w} / \mathrm{w}$ ). The $\mathrm{pH}$ was brought to the desired value (between 2.5 and 4.5) and kept constant during digestion by carefully adding $0.2 \mathrm{M} \mathrm{HCl}$. At regular time intervals $0.5-\mathrm{ml}$ portions were taken from the mixture and, after addition of o.I $\mathrm{ml} \mathrm{I} \mathrm{M} \mathrm{K}_{2} \mathrm{HPO}_{4}$ placed in ice to stop the hydrolysis. The samples were stored at $-20^{\circ}$. No difference in electrophoretic pattern was found for samples taken before and after freezing.

\section{Polyacrylamide gel electrophoresis}

Acrylamide and $N, N^{\prime}$-methylenebisacrylamide were obtained from Fluka (Switzerland). Gel dimensions were $5 \mathrm{~mm} \times 60 \mathrm{~mm}$. The protein samples, eight at a time, were diluted with a saccharose solution to a protein concentration of $I \%$. With a Hamilton microsyringe about $5 \mu \mathrm{l}$ were carefully layered onto the gel. The gels were 
stained in a solution containing $6 \mathrm{~g}$ amidoblack and $70 \mathrm{ml}$ acetic acid per 1 , and then washed in $7 \%(\mathrm{v} / \mathrm{v})$ acetic acid. Densitometer scans were made with a Kipp lin/log densitometer Model DD2 (Delft, Holland). In most cases electrophoresis was performed at $\mathrm{pH} 7.3$ (see ref. $\mathrm{I}_{3}$ ) or at $\mathrm{pH} 3.0$ in the presence of $6 \mathrm{M}$ urea. At $\mathrm{pH} 3.0$ an electrophoretic system as described by SCHOENMAKERs et al. ${ }^{14}$ was used. In both cases the gel concentration was $7.5 \%$. No sample gels were used.

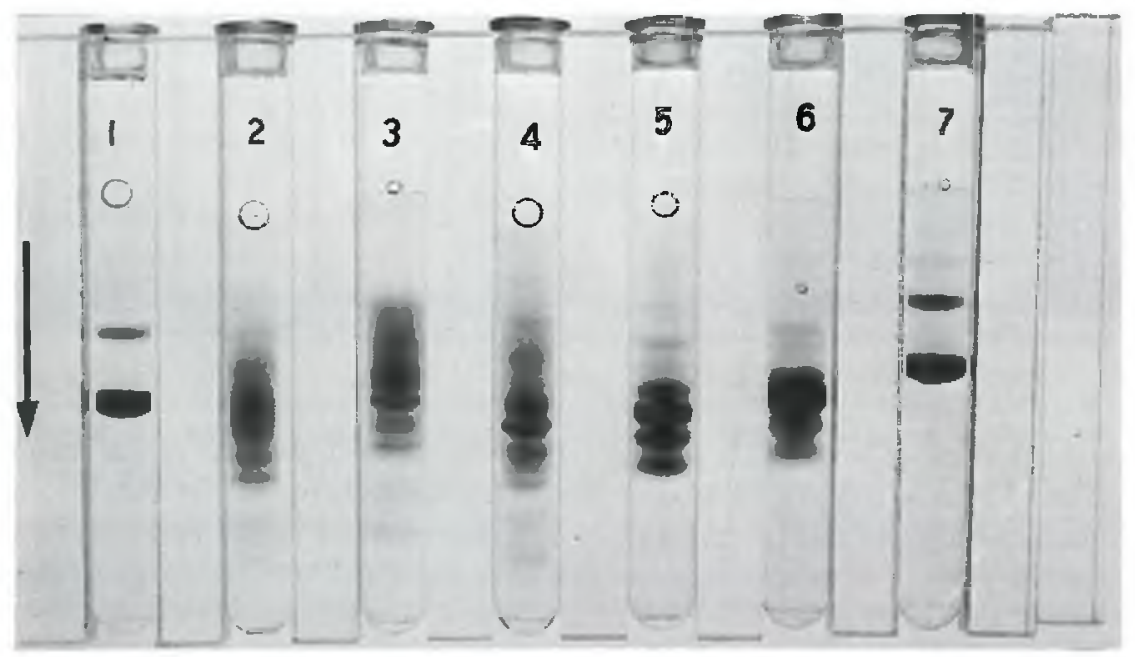

Fig. I. Electrophoresis at $\mathrm{pH} 7 \cdot 3$. The arrow indicates the direction of migration. The time of

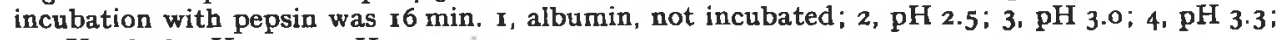
5. $\mathrm{pH}_{3.6} ; 6, \mathrm{pH}_{3.9} ; 7, \mathrm{pH}_{4.5}$.

\section{RESULTS AND DISCUSSION}

Fig. I shows the electrophoretic patterns of hydrolysates of albumin obtained after peptic digestion at $\mathrm{pH}$ values varying from 2.5 to 4.5 . The electrophoresis was performed at $\mathrm{pH}$ 7.3. Below $\mathrm{pH} 3.6$ rather complex patterns were obtained, but at $\mathrm{pH} 3.6$ and $\mathrm{pH} 3.9$ the pattern is simpler and consists of about five components. At $\mathrm{pH} 4.5$ no hydrolysis occurs, not even after digestion times up to ro5 min (not shown). The slowest migrating component in Gels $I$ and 7 is the dimer which is always present in commercial preparations of albumin. For all other experiments dimer-free albumin was therefore used. Since the enzymatic activity of pepsin is $\mathrm{pH}$ dependent, a comparison of digests obtained after the same time of hydrolysis but at different $\mathrm{pH}$ values becomes rather difficult. The time at which the same number of peptide bonds has been broken would be more suitable for this purpose. Experimentally, however, this is difficult to realize. For this reason, during each incubation samples were taken at time intervals varying from I to I05 min after the start of the hydrolysis. By doing this at various $\mathrm{pH}$ values information about the peptic digestion could be obtained. Representative results are shown in Figs. I and 2. In Fig. 2 densitometer scans of some of the gels are given. For each incubation the situation is given after 6 and $\mathrm{I} 6 \mathrm{~min}$ digestion. The patterns at $\mathrm{pH}$ values below 3.6 are complex 


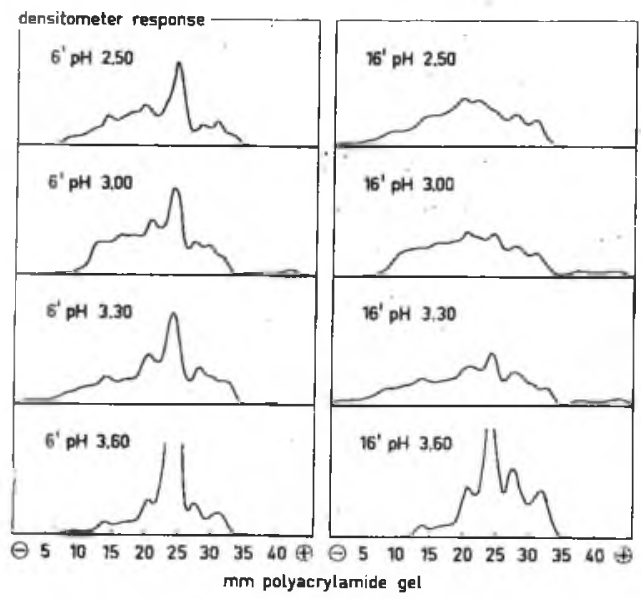

Fig. 2. Densitometer scans of the polyacrylamide gels. Electrophoresis was performed at $\mathrm{pH}_{7 \cdot 3}$. At each $\mathrm{pH}$ the results (obtained with dimer-free albumin) are given after incubation for $6 \mathrm{~min}$ and $16 \mathrm{~min}$.

even after a short time of hydrolysis $(6 \mathrm{~min})$. The well-defined pattern in the case of incubation at $\mathrm{pH} 3.6$ is still found after prolonged hydrolysis up to I05 $\mathrm{min}$.

These findings support the proposal that, as a consequence of the unfolding of the molecule below $\mathrm{pH} 3.6$, more sites become available for hydrolysis by the protease than between $\mathrm{pH} 3.6$ and 3.9 .

The number of components observed gives some information about the number of sites of hydrolysis. When for example there are two or three sites available for pepsin, six or ten fragments, respectively, can be expected. When electrophoresis is performed at $\mathrm{pH} 8.9$, at $\mathrm{pH} 7.3$ in the presence of sodium dodecyl sulphate or at $\mathrm{pH}$ 3.0, no fundamental difference in the patterns is observed, except that there appear to be six components instead of the five found at $\mathrm{pH} 7.3$ in the absence of sodium

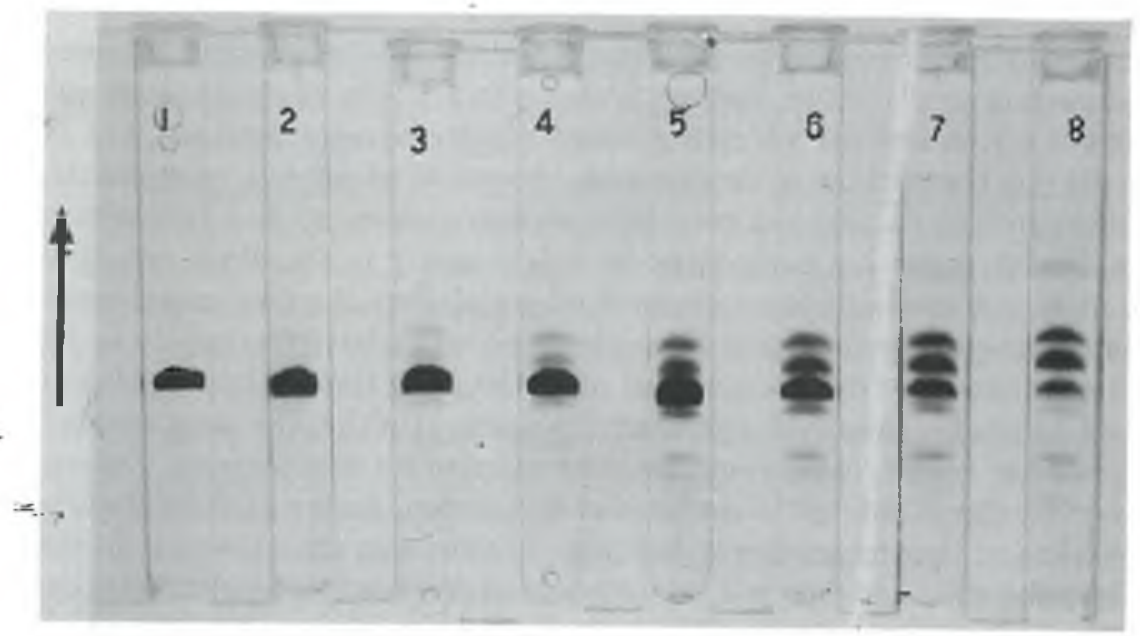

Fig. 3. Electrophoresis at $\mathrm{pH}$ 7.3. The arrow indicates the direction of migration. Incubation of dimer-free albumin with pepsin at $\mathrm{pH} 3.7 .1,0 \mathrm{~min} ; 2,2 \mathrm{~min} ; 3,4 \mathrm{~min} ; 4,6 \mathrm{~min} ; 5,10 \mathrm{~min}$; $6,20 \mathrm{~min} ; 7,40 \mathrm{~min} ; 8,105 \mathrm{~min}$. 


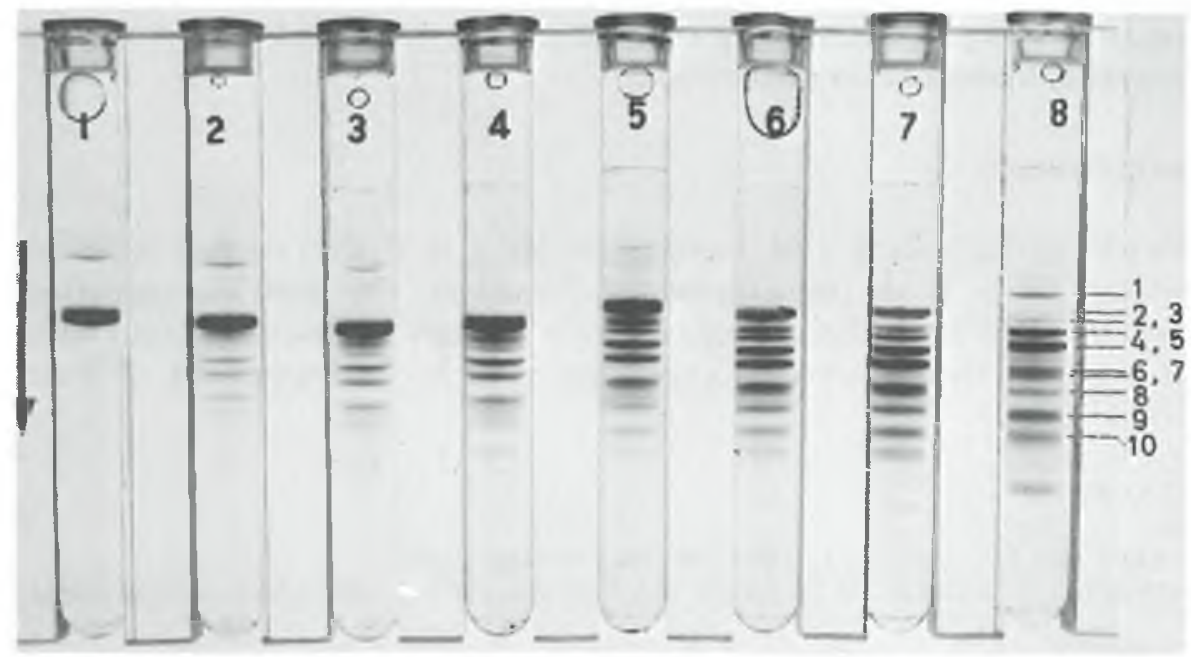

Fig. 4. Electrophoresis at $\mathrm{pH}_{3.0}$ in $6 \mathrm{M}$ urea. The arrow indicates the direction of migration. Incubation of dimer-free albumin with pepsin at $\mathrm{pH}$ 3.7. The same samples are used as in Fig. 3 . I, $0 \mathrm{~min} ; 2,2 \mathrm{~min} ; 3,4 \mathrm{~min} ; 4,6 \mathrm{~min} ; 5$, $10 \mathrm{~min} ; 6,20 \mathrm{~min} ; 7,40 \mathrm{~min} ; 8,105 \mathrm{~min}$.

dodecyl sulphate. However, at $\mathrm{pH} 3.0$ (fragments highly charged) in $6 \mathrm{M}$ urea (to prevent hydrogen and hydrophobic bonding between the fragments) ten components were found. This picture remained unchanged at urea concentrations varying from 2 to 7 M. In Figs. 3 and 4 are shown the results obtained with the same samples using two different electrophoretic systems. The existence of only five or six bands in the absence of urea is difficult to explain. Presumably aggregation of the peptide fragments is possible for only a few combinations.

Supposing that the hydrolysis of the "elementary" fragments of albumin is much slower than the hydrolysis at the linkages between these fragments, only four fragments will continuously increase in quantity after prolonged digestion, assuming that there are three linkages which can be hydrolysed by pepsin. Densitometer studies show the tendency of Fragments 4, 5, 9 and ro to survive (Fig. 4). While other components first accumulate and then diminish, only these fragments show an increase up to an incubation time of $105 \mathrm{~min}$. These observations support the model proposed by FOSTER? .

It is remarkable that pepsin, to which a broad specificity is normally ascribed can, under special circumstances, acquire a high specificity which seems to arise from the conformation of the substrate itself. In this respect it should be mentioned that the use of pepsin at $\mathrm{pH}$ values removed from its $\mathrm{pH}$ optimum for controlled hydrolysis of proteins has already been suggested by ScHLAMowiTz and co-workers ${ }^{15,16}$ who also found high-molecular-weight intermediates after peptic digestion of albumin at $\mathrm{pH} 3.5$.

From the experiments described, it is clear that the peptic digestion of albumin follows the Normal-Fast transition and although the enzyme is active up to $\mathrm{pH} 5.5$ (see refs. I6-r8), the hydrolysis of the Normal form of albumin is so slow that under our experimental conditions no hydrolysis is observed at $\mathrm{pH}$ values above 4.4.

The isolation and investigation of the ten fragments obtained after peptic 
hydrolysis is now in progress. A paper concerning the isolation and some properties of Fragments 8, 9 and ro is in preparation.

\section{ACKNOWLEDGEMENTS}

We wish to thank Mr. J. J. M. Joordens and Mr. J. H. F. Roef for their technical assistance and Dr. S. H. de Bruin for helpful discussions. This work was supported by a grant from the Netherlands Foundation for Chemical Research (S.O.N.) with financial aid from the Netherlands Organization for the Advancement of Pure Research (Z.W.O.).

\section{REFERENCES}

I J. T. Yang and J. F. Foster, J. Am. Chem. Soc., 76 (1954) I 588.

2 C. Tanford, J. G. Buzzell, D. G. Rands and S. A. Swanson, J. Am. Chem. Soc., 77 (1955) 6421.

3 W. F. Harrington, P. Johnson and R. H. Ottewill, Biochem. J., 62 (I956) 569.

4 K. Aoki and J. F. Foster, $J$. Am. Chem. Soc, 79 (1957) 3385.

5 W. J. Leonard and J. F. Foster, J. Biol. Chem., 236 (I96I) 2662.

6 M. Sogami and J. F. Foster, Biochemistry, 7 (I968) 2172.

7 J. F. Foster, in F. W. Putnam, The Plasma Proteins, Vol. I, Academic Press, New York, I960, p. 220.

8 G. Weber and L. B. Young, J. Biol. Chem., 239 (1964) 1415.

9 G. Franglen and G. R. E. SWaniker, Biochem. J., IO9 (I968) 107.

io T. Peters, JR., J. Biol. Chem., 240 (I965) PC 1866.

I I T. Peters, Jr. And C. Hawn, J. Biol. Chem., 242 (1967) 1566.

12 W. T. Shearer, R. A. Bradshaw, F. R. N. Gurd and T. Peters, Jr., J. Biol. Chem., 242 (1967) 5451 .

13 D. E. Williams and R. A. Reisfeld, Ann. N.Y. Acad. Sci., I2I (1964) 373.

I4 J. G. G. Schoenmakers, H. J. Hoenders and H. Bloemendal, Exptl. Eye Res., 7 (I968) I 72 .

i M. Schlamowitz, L. U. Peterson and F. C. Wissler, Arch. Biochem. Biophys., 92 (I961) 58.

i6 M. Schlamowitz and L. U. Peterson, J. Biol. Chem., 234 (1959) 3137.

I7 J. R. Cann and J. A. Klapper, JR., J. Biol. Chem., 236 (I96I) 2446.

I8 J. A. Klapper, Jr. and J. R. CanN, Arch. Biochem. Biophys., Io8 (1964) 531.

Biochim. Biophys. Acta, 236 (1971) 99-104 